\title{
From planning to implementation: explaining connections between adaptive management and population models
}

\author{
José J. Lahoz-Monfort*, Gurutzeta Guillera-Arroita and Cindy E. Hauser
}

Quantitative and Applied Ecology Group, School of Botany, University of Melbourne, Parkville, VIC, Australia

\section{Edited by:}

Stefano Allesina, University of

Chicago, USA

\section{Reviewed by:}

Kristen E. Dybala, University of California, Davis, USA

Laura Dee, University of California,

Santa Barbara, USA

*Correspondence:

José J. Lahoz-Monfort, School of

Botany, University of Melbourne,

Parkville, VIC 3010, Australia

e-mail: jose.lahoz@unimelb.edu.au
The management of natural systems often involves periodic interventions that must be decided without a complete understanding of how the system responds to our actions. It is in this situation of recurrent decision-making under uncertainty that adaptive management (AM) has been repeatedly advocated, with each decision round providing an opportunity to improve our knowledge in order to facilitate future decisions: the "learning while managing" tenet of AM. When the subject of management is a wildlife population (that is harvested, is a pest or is threatened with extinction), population models will be at the core of the AM process. We provide an overview of the steps in AM, from the set-up to the iterative phase, highlighting the central role that population models can play at different stages of the process of planning and implementing an AM program, as well as when analyzing the value of acquiring new information. We discuss the contexts in which these models have been applied in natural resource management and biodiversity conservation. We aim to bring this applied discipline to the attention of researchers interested in population dynamics, while stressing the relevance of these models for managers considering an AM approach.

Keywords: adaptive management, biodiversity conservation, decision theory, demography, growth model, natural resource management, uncertainty, value of information

\section{INTRODUCTION}

Management decisions regarding biodiversity conservation and natural resource management (NRM) often have to be made under uncertainty, which may arise from different sources (Regan et al., 2002; Williams et al., 2007, p. 61). When the management is directed at some animal or plant population rather than at an ecosystem or habitat, the uncertainties that impede straightforward decision-making are often underpinned by some aspect of population dynamics. From the specification of sustainable harvest rates (Nichols et al., 1995) to the management of pests (Shea et al., 2002) and endangered species (Runge, 2011), decisions need to be based on an understanding of population growth or demography, knowledge that can be formalized as population models. By population models we refer both to growth models (e.g., logistic or Ricker model; Ricker, 1954) and to models with explicit demographic dynamics (process models, e.g., based on a Leslie matrix; Caswell, 2001). The structure of such models, the value of the parameters within them, or how these are affected by environmental or human-related factors, are potential sources of uncertainty. Improving our knowledge about natural systems can be costly and/or time-consuming and waiting until uncertainties are resolved may not always be feasible in the face of pressing management decisions. In this context of recurrent decision-making under uncertainty "adaptive management" ("AM" hereafter) has often been advocated, such that knowledge can be updated over time and management actions adapted accordingly. It is therefore natural that population models play a key role in the application of the AM framework to programs that deal with populations of animals and plants.

The theory of AM was developed several decades ago in fisheries science (Walters and Hilborn, 1976, 1978; Smith and Walters, 1981) and then spread to other areas of NRM (Parma et al., 1998; Williams et al., 2007), particularly waterfowl hunting management (Nichols et al., 1995; Johnson et al., 1997). The last decade has seen a renewed interest in its application to biodiversity conservation, for both plant (Moore et al., 2011) and animal species (Rout et al., 2009; McDonald-Madden et al., 2010; Runge, 2013), as well as habitat-based approaches (Gerber et al., 2005; Moore and Conroy, 2006; McCarthy and Possingham, 2007). Although often dealing with a single species, multi-species problems have also been addressed using AM, including predator-prey systems with linked dynamics (Varley and Boyce, 2006; Martin et al., 2010) and sympatric species (Sainsbury, 1991; Smith et al., 2013).

In this paper we provide an overview of $\mathrm{AM}$, stressing the central role that population models play in the different stages of the process of planning and implementing an AM program (Figure 1), as well as in assessing the value of acquiring new information. With this review we hope to bring an applied discipline (AM) to the attention of population ecologists and other researchers interested in the development of population models, while highlighting the relevance of population modeling in the AM framework for researchers and managers that are new to this area and are considering applying an AM approach. 


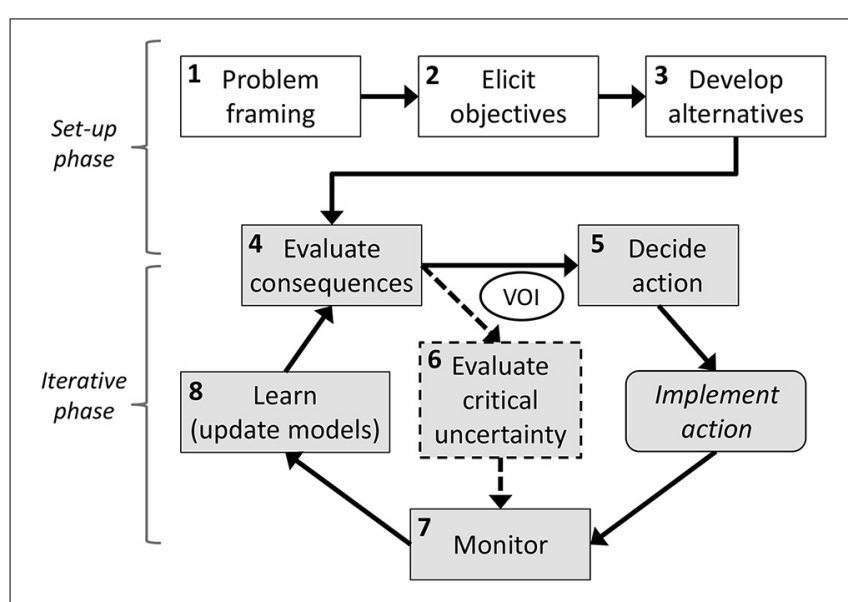

FIGURE 1 | Diagram of the main steps in adaptive management, as an iterative form of structured decision making (adapted from Runge, 2011), highlighting the two main phases. VOI stands for "value of information analysis."

\section{A QUICK TOUR OF ADAPTIVE MANAGEMENT: WHY AND HOW}

AM is sometimes described as "learning while managing" but this broad expression may be misleading and a more careful definition is warranted: the key to an AM program is that there must be careful planning for learning from the first steps of the program definition (Walters, 1986; Parma et al., 1998; Williams et al., 2007, p. 31), rather than learning opportunistically from management mistakes as they occur, in a trial-and-error approach. Therefore, monitoring within AM must be specifically targeted to increase our knowledge of the system in a way that improves future management actions, in an iterative process of decision-action-monitoring-evaluation (Figure 1).

We do not delve in the details of AM itself in this short paper; the reader is directed to different sources in the literature: guidelines for managers (Williams et al., 2007), more methodological sources about quantitative methods (Walters and Hilborn, 1978; Williams, 2011c), overviews and reviews of different aspects of AM (Runge, 2011; Williams, 2011a; Westgate et al., 2013), including discussions about bridging the research-practice gap (Gregory et al., 2006; Allen and Gunderson, 2011) and circumstances when an AM approach is not warranted (Walters, 1986). The human or managerial dimension of the problem (i.e., long-term institutional commitment or proper stakeholder engagement; Williams et al., 2007, p. 18) can also influence the suitability of an AM approach; while recognizing its relevance, we do not discuss it here.

We note that the emphasis in AM is in facilitating a decisionmaking process which, depending on the case, may not require indulging in aspects of the ecology or population dynamics of a species if these are not necessary in order to make the decision. For example, some decisions simply require distinguishing between probabilities of success of different management options (e.g., McCarthy and Possingham, 2007) independently of the mechanistic explanation behind their performance; in such cases a population model, although informative and more portable to other situations, may not be necessary for AM to proceed.
Adaptive management can be seen as an iterative form of structured decision making (Runge, 2011; Gregory et al., 2012), a common framework for the application of decision theory grounded in value-focused thinking, which emphasizes the early identification of management objectives (Figure 1). The following two sections describe the role that population models can play in the different steps of this process, which consists of a set-up phase and an iterative phase.

\section{SET-UP PHASE}

Properly setting the context for the decision is the focus of the set-up phase, in which the management problem is discussed and consensus between stakeholders is reached regarding objectives and acceptable alternative actions. The consequences of actions are evaluated and decision trade-offs clarified so that a preferred action can be identified.

At the problem-framing stage [step 1, Figure 1], population models may be used to help understand the biological context of the problem, e.g., to evaluate the current status of a species, threatening factors, or the impact of harvest levels. Such models may also influence how objectives (and measures to gage them) are articulated [step 2]. A set of alternative management actions [step 3] is often elicited based on conceptual models of why there is a problem to be solved (e.g., different actions may address different hypotheses about reproductive failure; Runge et al., 2011); this step can sometimes be supported by population models (e.g., including/excluding the effect of a competitor on survival of the target species). Evaluating the consequences of alternative actions [step 4] may be based on expert opinion but would ideally use predictions from those models. The final step is to identify a preferred management action [step 5], which often involves assessing trade-offs (e.g., an action that provides higher expected population growth may also involve higher risk of a poor outcome) and may require using different decision tools depending on the complexity of the decision context (e.g., multi-criteria decision analysis, dynamic programming).

Alternative hypotheses and management actions can sometimes be based on different beliefs about population dynamics even without defining population models explicitly (e.g., disease persistence and resulting population growth rates; McDonaldMadden et al., 2010); parameterization may be based on expert elicitation during the set-up phase (Runge et al., 2011). In general, the structure chosen for the population model must take into account how it will be used to make a decision and to test alternative actions (Converse et al., 2013). It must therefore be able to reflect the set of hypotheses regarding the effect that alternative actions have on demography or population growth of the managed population, and provide good metrics for the objectives.

Objectives, model structures and uncertainties depend on the type of managed resource. For harvested populations, objectives are usually linked to maximizing long-term yield, by establishing optimal harvest rates. Early fisheries AM programs were based on a growth model with uncertain parameter values (e.g., intrinsic growth rate, Walters and Hilborn, 1976; density-dependence, Smith and Walters, 1981) or uncertain model structure (e.g., Ricker vs. Beverton-Holt stock-recruitment models, Walters and Hilborn, 1976). For waterfowl harvests in the US (Nichols et al., 
1995; Johnson et al., 1997), alternative demographic models have been used to reflect relevant hypotheses about mortality being additive or compensatory (Williams et al., 1996) or the strength of density-dependence in recruitment (Johnson et al., 1997). In species conservation problems, objectives are usually related to population viability (Converse et al., 2013). This objective may be explicit (either maximizing viability or minimizing probability of extinction; Bakker and Doak, 2009) or defined indirectly through maximizing population abundance (Bearlin et al., 2002; Runge, 2013; Smith et al., 2013), number of populations (Moore et al., 2011) or population growth rate (McDonald-Madden et al., 2010), and may include thresholds (e.g., productivity above some level, Martin et al., 2010) or multiple competing objectives (e.g., harvest and conservation, Varley and Boyce, 2006; Smith et al., 2013). All these metrics require population models for their calculation. Again, the uncertainty that complicates decisionmaking may be related to demographic parameters (e.g., survival, Rout et al., 2009; Runge, 2013; or productivity, Smith et al., 2013) or model structure (Martin et al., 2010; Moore et al., 2011). The issue of population control is in a way inverse to that of conservation: managers attempt to keep the population of the problem species under some level, or even aim at eradicating it in the case of invasive species. AM has been proposed for the control of native species (e.g., overgrazing, Kaji et al., 2010; or predators, Martin et al., 2010) as well as alien invasive species (Parkes et al., 2006) and forestry/agricultural pests (Shea et al., 2002). Applications of AM to pest control in agriculture and forestry are still surprisingly rare given that these systems lend themselves well to experimental manipulation (Parma et al., 1998; Shea et al., 2002).

The population models defined during the setup phase are sometimes used in simulations to evaluate different management options before proceeding to the implementation of an AM program, by simulating the complete cycle of decision-actionmonitoring-evaluation (Bearlin et al., 2002; Smith et al., 2013), an approach sometimes termed Management Strategy Evaluation (Bunnefeld et al., 2011). Demographic models can also be used in detailed simulations of population trajectories based on demographic parameters to evaluate management actions in terms of the resulting extinction risk, a process commonly known as "population viability analysis" or PVA (e.g., studies cited in Converse et al., 2013). A stronger integration of PVA into AM has been advocated as a way to explicitly link monitoring and management models in a single simulation framework ("Population Viability Management," Bakker and Doak, 2009).

\section{ITERATIVE PHASE}

The steps outlined in the previous section lead to a decision in a structured way. A key element in AM (particularly the "decisiontheoretic" school of thought; Runge, 2011) is a subsequent iterative phase of monitoring to help resolve our uncertainty about decision-making, updating the belief in alternative hypotheses about the system, and adapting future actions accordingly (Figure 1).

This iterative process requires the articulation of critical uncertainty in the form of competing predictive population models [step 6]. This step strongly influences the design of the necessary monitoring program [step 7] so that it is targeted at resolving the critical uncertainties about the system that impede clear management decisions. Learning [step 8] comes from comparing the responses predicted by the competing population models to the response observed by monitoring the population; this allows updating the belief in the different hypotheses represented by these models. A key feature in AM is that we now adapt our subsequent decision-making in the light of the new knowledge, and enter a new iteration of the cycle.

Different actions are expected to generate different responses, and this often translates to different kinds and speeds of learning. Thus, there is a trade-off between the potential future benefits of learning from novel actions and data, against the immediate benefits of managing with what we know. A classic example from fisheries is a heavily fished population. We might assume a logistic growth model where we have good knowledge of the intrinsic growth rate but high uncertainty about carrying capacity. Maximum sustainable yield is a function of carrying capacity so managers may consider continuing with the intensive fishing or alternatively allowing the population to grow and approach carrying capacity by reducing fishing rates for a few years in order to reveal the population's true maximum sustainable yield (Walters and Hilborn, 1976). Two main approaches exist to deal with this type of trade-offs (Walters, 1986; Williams, 2011b): one can experiment actively (deviate from what appears the best option at a given time, in order to improve understanding so that future decisions can be improved-active adaptive management); or learn in a more passive fashion (act according to best current knowledge, but plan to learn from the outcome in order to improve future decisions_-passive adaptive management). By contrast, we can also develop strategies that maximize distinction among hypotheses at the conclusion of the management program without any regard for management objectives (Probert et al., 2011).

Less structured approaches can also be used for decisionmaking, with AM proceeding on a suboptimal trajectory that still delivers learning alongside management (Williams et al., 2007, p. 33; Converse et al., 2013). Whenever possible, optimizing the decision-making process will improve the predicted benefits of an AM approach. For both active and passive AM, quantitative methods exist to provide an optimal schedule of actions so that an overall objective is maximized for a given timeframe. Optimization methods most commonly assume that populations possess first-order Markovian dynamics, such that all feedback from the current action is observed in the next time step. Any delayed responses need to be incorporated as state variables, which increase the complexity of the problem.

Stochastic dynamic programming has been used widely to calculate optimal schedules (e.g., Walters and Hilborn, 1976; Johnson et al., 1997; McCarthy and Possingham, 2007), and uses discrete transition models of system and knowledge change over time. This technique is typically constrained to small statespaces and simple knowledge constructions, involving discrete approximation of continuous population models. Walters (1986) recommended Kalman filters to approximate more complex (but still discrete) knowledge transitions, and wide-sense dual control algorithms to approximate optimal management schedules. 
Other methods can accommodate continuity in knowledge states for a small number of distinct alternative population models (Williams, 2011c). For more complex structures, artificial intelligence methods and algorithms for discretized belief Markov Decision Processes (Fackler and Pacifici, 2014), Partially Observable Markov Decision Processes (Nicol et al., 2013) and Mixed Observability Markov Decision Processes (Chadès et al., 2012) show promise for developing near-optimal management schedules. These approaches assume discrete population model transitions between time steps; thus appropriate discretization of population models will require a trade-off of predictive accuracy against the computational burden of optimizing over a large statespace, although in some cases few states really matter (Nicol and Chadès, 2012).

\section{VALUE OF INFORMATION ANALYSIS}

Within the idea of "learning while managing" sits the concept of acquiring new information to improve the decision-making process. A set of quantitative tools from decision theory, collectively called "Value of Information analysis" (VOI), allow investigation of the value of collecting additional information to resolve or reduce uncertainty (Runge et al., 2011). The most common techniques are Expected Value of Perfect Information (EVPI; resolving all uncertainty), Expected Value of Partial Information (EVPI; resolving a subset of uncertainty, e.g., one particular hypothesis) and Expected Value of Sample Information (EVSI; for a data sample of a given size).

Analyzing the value of information can help: (1) concentrate the learning to specific aspects of uncertainty that will improve decision-making more quickly (high EVPI) and/or avoid doing research on those aspects that do not contribute significantly (low EVPI); (2) decide the amount of information that has to be collected to achieve a given level of improvement in decision-making (EVSI); or (3) indicate when overall it is not worth attempting to learn about the system (low EVPI) or at least given the available resources or capabilities to monitor (low EVSI for realistic sample sizes). After all, the value of AM hinges on having high value of information and the means to acquire enough data to achieve sufficient power (Runge, 2011). VOI analysis could be conducted before committing to an AM program and at the beginning of each management cycle if our knowledge has changed substantially; sequential VOI analysis has been proposed (Griffin et al., 2010) but we are not aware of any application in environmental management.

Population models can play a key role in conducting VOI analyses, which require quantifying the effect of alternative management actions on some parameter(s) of interest, under alternative hypotheses about the system. Population modelers must therefore translate these hypotheses into different model structures or parameter values so that the impact of actions can be predicted. For example, in Runge et al. (2011) expert elicitation provided expected survival probabilities under several reproductive failure hypotheses and management strategies; if enough data were available these probabilities could be estimated using alternative models. Furthermore, VOI analysis is based on demographic parameters or population growth, but the managers that are in a position to decide whether extra data collection is worth its cost often prefer to work in terms of the population impact of these demographic processes, e.g., persistence or extinction risk. Population models can also be used to convert between these currencies, e.g., translating a change in expected survival probability due to resolving some uncertainty to an expected change in extinction risk. Population viability analysis (PVA), which includes a demographic model at their core, is particularly useful for this purpose. In summary, we believe VOI analysis can play an important role in informing research agendas for population modeling since it may indicate which aspects of the demography of a population are worth investigating.

\section{CONCLUSIONS}

Adaptive management represents ecological intervention with a structured plan for learning about key uncertainties in a natural system of interest (Parma et al., 1998). Issues of harvest, pest management and conservation all involve fundamental objectives concerned with future population status: to maintain, reduce or increase their levels, respectively. Since demographic parameters govern the fate of the population under management, population models can provide the necessary predictive link between management alternatives and objectives (Converse et al., 2013) and can therefore be central to adaptive management programs. Calls to extend the use of AM in decisions regarding wildlife populations are common in the literature (Parma et al., 1998; Shea et al., 2002; Williams et al., 2007; Runge, 2011; Williams, 2011a; Converse et al., 2013). We believe a more widespread application of adaptive management in natural resource management and biodiversity conservation will provide opportunities for stronger collaboration between population modelers, managers and other stakeholders, to achieve a better integration of science and management.

\section{ACKNOWLEDGMENTS}

This work was supported by the ARC Centre of Excellence for Environmental Decisions and the National Environment Research Program (NERP) Decisions Hub. We would like to thank Iadine Chadès for useful discussion regarding optimization methods.

\section{REFERENCES}

Allen, C. R., and Gunderson, L. H. (2011). Pathology and failure in the design and implementation of adaptive management. J. Environ. Manage. 92, 1379-1384. doi: 10.1016/j.jenvman.2010.10.063

Bakker, V. J., and Doak, D. F. (2009). Population viability management: ecological standards to guide adaptive management for rare species. Front. Ecol. Environ. 7, 158-165. doi: 10.1890/070220

Bearlin, A. R., Schreiber, E. S. G., Nicol, S. J., Starfield, A. M., and Todd, C. R. (2002). Identifying the weakest link: simulating adaptive management of the reintroduction of a threatened fish. Can. J. Fish. Aquat. Sci. 59, 1709-1716. doi: 10.1139/f02-140

Bunnefeld, N., Hoshino, E., and Milner-Gulland, E. J. (2011). Management strategy evaluation: a powerful tool for conservation? Trends Ecol. Evol. 26, 441-447. doi: 10.1016/j.tree.2011.05.003

Caswell, H. (2001). Matrix Population Models: Construction, Analysis and Interpretation. Sunderland: Sinauer Associates.

Chadès, I., Carwardine, J., Martin, T. G., Nicol, S., Sabbadin, R., and Buffet, O. (2012). "MOMDPs: a solution for modelling adaptive management problems," in Twenty-Sixth AAAI Conference on Artificial Intelligence (Toronto, ON: AAAI Press). 
Converse, S. J., Moore, C. T., and Armstrong, D. P. (2013). Demographics of reintroduced populations: estimation, modeling, and decision analysis. J. Wildl. Manage. 77, 1081-1093. doi: 10.1002/jwmg.590

Fackler, P., and Pacifici, K. (2014). Addressing structural and observational uncertainty in resource management. J. Environ. Manage. 133, 27-36. doi: 10.1016/j.jenvman.2013.11.004

Gerber, L. R., Beger, M., McCarthy, M. A., and Possingham, H. P. (2005). A theory for optimal monitoring of marine reserves. Ecol. Lett. 8, 829-837. doi: 10.1111/j.1461-0248.2005.00784.x

Gregory, R., Failing, L., Harstone, M., Long, G., Mcdaniels, T., and Ohlson, D. (2012). Structured Decision Making: A Practical Guide to Environmental Management Choices. Chichester, UK: John Wiley \& Sons. doi: 10.1002/978144 4398557

Gregory, R., Ohlson, D., and Arvai, J. (2006). Deconstructing adaptive management: criteria for applications to environmental management. Ecol. Appl. 16, 2411-2425. doi: 10.1890/1051-0761(2006)016[2411:DAMCFA]2.0.CO;2

Griffin, S., Welton, N. J., and Claxton, K. (2010). Exploring the research decision space: the expected value of information for sequential research designs. Med. Decis. Making 30, 155-162. doi: 10.1177/0272989X09344746

Johnson, F. A., Moore, C. T., Kendall, W. L., Dubovsky, J. A., Caithamer, D. F., Kelley, J. R., et al. (1997). Uncertainty and the management of mallard harvests. J. Wildl. Manage. 61, 202-216. doi: 10.2307/3802429

Kaji, K., Saitoh, T., Uno, H., Matsuda, H., and Yamamura, K. (2010). Adaptive management of sika deer populations in Hokkaido, Japan: theory and practice. Popul. Ecol. 52, 373-387. doi: 10.1007/s10144-010-0219-4

Martin, J., O'connell, A. F., Kendall, W. L., Runge, M. C., Simons, T. R., Waldstein, A. H., et al. (2010). Optimal control of native predators. Biol. Conserv. 143, 1751-1758. doi: 10.1016/j.biocon.2010.04.023

McCarthy, M. A., and Possingham, H. P. (2007). Active adaptive management for conservation. Conserv. Biol. 21, 956-963. doi: 10.1111/j.1523-1739.2007.00677.x

McDonald-Madden, E., Probert, W. J. M., Hauser, C. E., Runge, M. C., Possingham, H. P., Jones, M. E., et al. (2010). Active adaptive conservation of threatened species in the face of uncertainty. Ecol. Appli. 20, 1476-1489. doi: 10.1890/090647.1

Moore, C. T., and Conroy, M. J. (2006). Optimal regeneration planning for oldgrowth forest: addressing scientific uncertainty in endangered species recovery through adaptive management. Forest Sci. 52, 155-172.

Moore, C. T., Fonnesbeck, C. J., Shea, K., Lah, K. J., McKenzie, P. M., Ball, L. C., et al. (2011). An adaptive decision framework for the conservation of a threatened plant. J. Fish Wildl. Manage. 2, 247-261. doi: 10.3996/012011-JFWM-007

Nichols, J. D., Johnson, F. A., and Williams, B. K. (1995). Managing NorthAmerican waterfowl in the face of uncertainty. Annu. Rev. Ecol. Syst. 26, 177-199. doi: 10.1146/annurev.es.26.110195.001141

Nicol, S., Buffet, O., Iwamura, T., and Chadès, I. (2013). "Adaptive management of migratory birds under sea level rise," in Twenty-Third International Joint Conference on Artificial Intelligence (Beijing: AAAI Press).

Nicol, S., and Chadès, I. (2012). Which states matter? an application of an intelligent discretization method to solve a continuous POMDP in conservation biology. PLoS ONE 7:e28993. doi: 10.1371/journal.pone.0028993

Parkes, J. P., Robley, A., Forsyth, D. M., and Choquenot, D. (2006). Adaptive management experiments in vertebrate pest control in New Zealand and Australia. Wildl. Soc. Bull. 34, 229-236. doi: 10.2193/0091-7648(2006)34[229:AMEIVP] 2.0.CO;2

Parma, A. M., Amarasekare, P., Mangel, M., Moore, J., Murdoch, W. W., Noonburg, E., et al. (1998). What can adaptive management do for our fish, forests, food, and biodiversity? Integr. Zool. 1, 16-26.

Probert, W. J. M., Hauser, C. E., McDonald-Madden, E., Runge, M. C., Baxter, P. W. J., and Possingham, H. P. (2011). Managing and learning with multiple models: objectives and optimization algorithms. Biol. Conserv. 144, 1237-1245. doi: 10.1016/j.biocon.2010.07.031

Regan, H. M., Colyvan, M., and Burgman, M. A. (2002). A taxonomy and treatment of uncertainty for ecology and conservation biology. Ecol. Appl. 12, 618-628. doi: 10.1890/1051-0761(2002)012[0618:ATATOU]2.0.CO;2

Ricker, W. E. (1954). Stock and recruitment. J. Fish. Res. Board Can. 11, 559-623. doi: 10.1139/f54-039

Rout, T. M., Hauser, C. E., and Possingham, H. P. (2009). Optimal adaptive management for the translocation of a threatened species. Ecol. Appl. 19, 515-526. doi: 10.1890/07-1989.1
Runge, M. C. (2011). An introduction to adaptive management for threatened and endangered species. J. Fish Wildl. Manage. 2, 220-233. doi: 10.3996/082011JFWM-045

Runge, M. C. (2013). Active adaptive management for reintroduction of an animal population. J. Wildl. Manage. 77, 1135-1144. doi: 10.1002/jwmg.571

Runge, M. C., Converse, S. J., and Lyons, J. E. (2011). Which uncertainty? using expert elicitation and expected value of information to design an adaptive program. Biol. Conserv. 144, 1214-1223. doi: 10.1016/j.biocon.2010.12.020

Sainsbury, K. J. (1991). Application of an experimental approach to management of a tropical multispecies fishery with highly uncertain dynamics. ICES Marine Sci. Symp. 193, 301-320.

Shea, K., Possingham, H. P., Murdoch, W. W., and Roush, R. (2002). Active adaptive management in insect pest and weed control: intervention with a plan for learning. Ecol. Appli. 12, 927-936. doi: 10.1890/10510761(2002)012[0927:AAMIIP]2.0.CO;2

Smith, A. D. M., and Walters, C. J. (1981). Adaptive management of stockrecruitment systems. Can. J. Fish. Aquat. Sci. 38, 690-703. doi: 10.1139/f81-092

Smith, D. R., McGowan, C. P., Daily, J. P., Nichols, J. D., Sweka, J. A., and Lyons, J. E. (2013). Evaluating a multispecies adaptive management framework: must uncertainty impede effective decision-making? J. Appl. Ecol. 50, 1431-1440. doi: $10.1111 / 1365-2664.12145$

Varley, N., and Boyce, M. S. (2006). Adaptive management for reintroductions: updating a wolf recovery model for Yellowstone National Park. Ecol. Modell. 193, 315-339. doi: 10.1016/j.ecolmodel.2005.09.001

Walters, C. (1986). Adaptive Management of Renewable Resources. New York, NY: Macmillan Publishing Co.

Walters, C. J., and Hilborn, R. (1976). Adaptive-control of fishing sysetems. J. Fish. Res. Board Can. 33, 145-159. doi: 10.1139/f76-017

Walters, C. J., and Hilborn, R. (1978). Ecological optimization and adaptive management. Annu. Rev. Ecol. Syst. 9, 157-188. doi: 10.1146/annurev.es.09.110178. 001105

Westgate, M. J., Likens, G. E., and Lindenmayer, D. B. (2013). Adaptive management of biological systems: a review. Biol. Conserv. 158, 128-139. doi: 10.1016/ j.biocon.2012.08.016

Williams, B. K. (2011a). Adaptive management of natural resources-framework and issues. J. Environ. Manage. 92, 1346-1353. doi: 10.1016/j.jenvman.2010. 10.041

Williams, B. K. (2011b). Passive and active adaptive management: approaches and an example. J. Environ. Manage. 92, 1371-1378. doi: 10.1016/j.jenvman.2010. 10.039

Williams, B. K. (2011c). Resolving structural uncertainty in natural resources management using POMDP approaches. Ecol. Modell. 222, 1092-1102. doi: 10.1016/ j.ecolmodel.2010.12.015

Williams, B. K., Johnson, F. A., and Wilkins, K. (1996). Uncertainty and the adaptive management of waterfowl harvests. J. Wildl. Manage. 60, 223-232. doi: $10.2307 / 3802220$

Williams, B. K., Szaro, R. C., and Shapiro, C. D. (2007). Adaptive Management: The U.S. Department of the Interior Technical Guide. Adaptive Management Working Group. Washington, DC: Department of the Interior. Available online at: http://www.doi.gov/ppa/upload/TechGuide-WebOptimized-2.pdf

Conflict of Interest Statement: The authors declare that the research was conducted in the absence of any commercial or financial relationships that could be construed as a potential conflict of interest.

Received: 21 June 2014; accepted: 14 September 2014; published online: 02 October 2014.

Citation: Lahoz-Monfort JJ, Guillera-Arroita G and Hauser CE (2014) From planning to implementation: explaining connections between adaptive management and population models. Front. Ecol. Evol. 2:60. doi: 10.3389/fevo.2014.00060

This article was submitted to Population Dynamics, a section of the journal Frontiers in Ecology and Evolution.

Copyright (c) 2014 Lahoz-Monfort, Guillera-Arroita and Hauser. This is an openaccess article distributed under the terms of the Creative Commons Attribution License (CC BY). The use, distribution or reproduction in other forums is permitted, provided the original author(s) or licensor are credited and that the original publication in this journal is cited, in accordance with accepted academic practice. No use, distribution or reproduction is permitted which does not comply with these terms. 